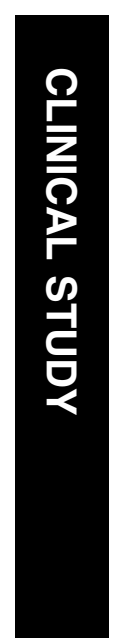

\section{Macular hole surgery without prone positioning}

\begin{abstract}
Purpose To investigate the role of vitrectomy without prone posturing in the anatomic and functional outcome of macular hole surgery (MHS).

Methods Forty-one consecutive eyes of 41 patients with stage II-IV full-thickness macular holes underwent pars plana vitrectomy and $16 \% \mathrm{C} 3 \mathrm{~F} 8$ tamponade. In 25 cases posturing group $(\mathrm{P})$, subjects were instructed to assume prone positioning for $\mathbf{1 0}$ days postoperatively, whereas in 16 cases nonposturing group (NP) patients were advised to avoid lying supine but no other posturing instructions were given. Preoperative, intraoperative and postoperative clinical data were collected, with macular hole closure rate and change in LogMAR visual acuity, contrast sensitivity, metamorphopsia, and 25-Visual Function Questionnaire (VFQ-25) being the primary outcome measures.
\end{abstract}

Results Over a mean follow-up of $4.2 \pm 1.2$ months, anatomical hole closure was noted in $22 / 25(88 \%)$ and $14 / 16(87.5 \%)$ in groups $P$ and NP respectively. Visual acuity improved by a mean of eight letters and there was no significant difference in the two groups $(P=0.724)$. Similarly, postoperative prone posturing did not have an effect on the final contrast sensitivity, metamorphopsia, and VFQ-25 composite scores $(P=0.238, P=0.472$, and $P=0.87$, respectively). However, eyes in group NP developed significantly more severe cataract in the early postoperative period $(P=0.02)$.

Conclusions Prone posturing following MHS provides no functional or anatomic benefit but it is associated with slower progression of cataract. Combined phacovitrectomy without face down positioning may be considered for all phakic patients undergoing MHS.

Eye (2007) 21, 802-806; doi:10.1038/sj.eye.6702339; published online 31 March 2006

Keywords: macular hole; prone posturing
PG Tranos ${ }^{1,3}$, NM Peter ${ }^{2,3}, \mathrm{R}$ Nath $^{2,3}, \mathrm{M}$ Singh2, S Dimitrakos ${ }^{1}$, D Charteris ${ }^{1}$ and $C$ Kon $^{2}$

\section{Introduction}

Idiopathic full-thickness macular hole (FTMH) is an important cause of central visual loss in the elderly, with more than $70 \%$ of cases being women in their seventh or eighth decade of life. ${ }^{1}$

Vitrectomy with internal tamponade of the hole is regarded as being essential for successful macular hole surgery (MHS). Although never proven in a controlled trial, postoperative strict prone posturing is generally considered a part of the traditional postoperative routine. ${ }^{2-4}$ This regime compromises the postoperative quality of life (QOL) of all patients, whereas it makes MHS almost impossible for individuals with mental or physical limitations.

The purpose of this controlled prospective study is to evaluate further the role of vitrectomy without prone posturing in the anatomical and functional outcome of MHS.

\section{Materials and methods}

This prospective study enrolled subjects who were due to undergo idiopathic MHS in Moorfields Eye hospital, London, and Worthing Hospital, Worthing, between May 2003 and June 2004. Eligibility criteria included idiopathic stage II-IV FTMH, whereas patients with clinically significant coexisting ocular pathology such as glaucoma and age-related macular degeneration or history of previous vitreoretinal intervention were excluded.,6 Subjects were also required to pass an abbreviated version of the Folstein Mini-Mental State examination. ${ }^{7}$

\section{Study design and procedures}

Habitual and best-corrected visual acuity for distance and near was measured at 4 and $0.4 \mathrm{~m}$, respectively, using two modified Early Treatment Diabetic Retinopathy Study (ETDRS) charts, at standard ambient light. Visual acuity was recorded as the number of letters read correctly from $0(20 / 250)$ to $70(20 / 10)$ for distance vision and from 0 to $75(20 / 15)$ for near vision. $^{8}$
Fort Lauderdale, USA, May 2005

This work has been Association for Research in 
Central metamorphopsia was evaluated by measuring the number of squares representing distortion on Amsler chart. Contrast sensitivity was measured by means of Pelli-Robson chart at $1 \mathrm{~m}$.

Baseline examination also included dilated slit-lamp biomicroscopy. The presence and severity of cataracts were graded using the Lens Opacities Classification System III (LOCS III) reference standards. ${ }^{9}$ The size of macular hole was measured with a $66 \mathrm{D}$ lens and it was classified as stage II, III, or IV. .,6 $^{5}$

Subjects were asked to self-administer the National Eye Institute 25-Item Visual Function Questionnaire (VFQ-25). Subscales were scored on a 0-100 point scale and the VFQ-25 composite (overall) score was calculated as the unweighted average response to all items, excluding the general health rating question. ${ }^{10}$

The surgical technique included standard three-port pars plana vitrectomy and induction of posterior hyaloid separation when required. All patients underwent internal limiting membrane peel using $0.15 \%$ Trypan blue to assist visualisation with subsequent $16 \% \mathrm{C}_{3} \mathrm{~F}_{8}$ internal gas tamponade. Subjects who underwent surgery at Moorfields and Worthing Hospital were assigned to group P (posturing) and NP (non-posturing), respectively. Group P subjects were instructed to assume prone positioning for 10 days postoperatively, whereas group NP patients were advised to avoid lying supine but no other posturing instructions were given.

Subjects were reviewed 1 day, 3 weeks, and 4 months postoperatively, and any peroperative complications were documented. At the 4-month appointment, complete baseline examination was repeated, the anatomic outcome of the operation was recorded, and patients again completed the QOL questionnaires.

\section{Results}

\section{Patient demographics (see Table 1)}

Forty-one eyes of 41 consecutive patients were recruited into the study over a period of 13 months, of which 25 and 16 patients were assigned to group $\mathrm{P}$ and group NP, respectively. There was no statistically significant difference between the two groups regarding the duration $(P=0.89)$, size and stage of macular hole ( $P=0.07$ and 0.49 , respectively), and baseline visual acuity ( $P=0.39$, Mann-Whitney U-test).

\section{Anatomical outcome}

Over a mean follow-up of $4.3 \pm 1.1$ months, primary successful macular hole closure (hole not visible
Table 1 Baseline characteristics of recruits (41 eyes of 41 patients)

\begin{tabular}{|c|c|}
\hline \multicolumn{2}{|l|}{ Age (years) } \\
\hline Range & $51-83$ \\
\hline Mean \pm SD & $70 \pm 7$ \\
\hline \multicolumn{2}{|l|}{$\operatorname{Sex}$} \\
\hline Male & $18(44 \%)$ \\
\hline Female & $23(56 \%)$ \\
\hline \multicolumn{2}{|l|}{ Race } \\
\hline White & $37(90 \%)$ \\
\hline Black & $2(5 \%)$ \\
\hline Indian & $2(5 \%)$ \\
\hline \multicolumn{2}{|l|}{ Eye } \\
\hline Right & $53 \%$ \\
\hline Left & $47 \%$ \\
\hline \multicolumn{2}{|l|}{ Spherical equivalent in operated eye } \\
\hline Range & $(-8.8)-(2.8)$ \\
\hline Mean \pm SD & $-0.26 \pm 2.32$ \\
\hline \multicolumn{2}{|l|}{ Lens status } \\
\hline Phakic & $39(95 \%)$ \\
\hline Pseudophakic & $2(5 \%)$ \\
\hline \multicolumn{2}{|l|}{ LogMAR distance visual acuity (number of letters) } \\
\hline Range & $3-42$ \\
\hline Mean \pm SD & $25 \pm 12$ \\
\hline \multicolumn{2}{|l|}{ LogMAR near visual acuity (number of letters) } \\
\hline Range & $17-52$ \\
\hline Mean \pm SD & $34 \pm 10$ \\
\hline \multicolumn{2}{|l|}{ Contrast sensitivity } \\
\hline Range & $0.45-1.65$ \\
\hline Mean \pm SD & $1.4 \pm 0.3$ \\
\hline \multicolumn{2}{|l|}{ Metamorphopsia (number of squares on Amsler chart) } \\
\hline Range & $9-280$ \\
\hline Mean \pm SD & $59 \pm 66$ \\
\hline \multicolumn{2}{|l|}{ Stage of macular hole } \\
\hline II & $7(17 \%)$ \\
\hline III & $28(68 \%)$ \\
\hline IV & $6(15 \%)$ \\
\hline \multicolumn{2}{|l|}{ Size of macular hole $(\mu \mathrm{m})$} \\
\hline Range & $200-750$ \\
\hline Mean \pm SD & $485 \pm 127$ \\
\hline Duration of macular hole (range in months) & $13.6 \pm 34.4$ \\
\hline
\end{tabular}

$\mathrm{SD}$, standard deviation.

postoperatively) was achieved in $22 / 25(88 \%)$ and $14 / 16$ $(87.5 \%)\left(P=1.0, \chi^{2}\right.$ test $)$ in groups $P$ and NP, respectively. No case of macular hole re-opening was recorded during the study period. 
Univariate analysis revealed that surgery in smaller macular holes was significantly more likely to achieve a favourable postoperative anatomic result $(P=0.03$, Spearman correlation test).

\section{Functional outcome}

Changes in visual function parameters following MHS in the posturing and non-posturing groups are summarised in Table 2.

There was significant improvement in visual acuity and central distortion postoperatively in both groups; however, contrast sensitivity did not change significantly in either group. There was no statistically significant difference in outcome between the two groups.

\section{QOL questionnaire}

Mean values for change in VFQ-25 subscale and composite scores following macular hole surgery in the posturing and non-posturing groups are documented in Table 3. All VFQ-25 mean subscale scores improved postoperatively, and analysis showed statistically significant improvement in general vision $(P<0.001)$, near activities $(P=0.042)$, and composite score $(P=0.01$, Wilcoxon signed rank test). However, there was no significant difference between the postured and nonpostured groups in any of the subscale or composite scores.

\section{Complications of surgery}

The incidence of intra- and postoperative complications is listed in Table 4 .

Table 2 Comparison of changes in visual function following macular hole surgery with and without prone positioning

\begin{tabular}{|c|c|c|c|c|c|}
\hline \multirow[t]{2}{*}{ Visual function parameter } & \multicolumn{2}{|c|}{ Postured $(P)$} & \multicolumn{2}{|c|}{ Non-postured (NP) } & \multirow[t]{2}{*}{ P-value } \\
\hline & Pre-MHS & Post-MHS & Pre-MHS & Post-MHS & \\
\hline ETDRS visual acuity & & & & & 0.75 \\
\hline Distance & $22 \pm 13$ & $28 \pm 15$ & $29 \pm 9$ & $39 \pm 12$ & \\
\hline Near & $33 \pm 10$ & $41 \pm 14$ & $36 \pm 8$ & $44 \pm 13$ & \\
\hline \multicolumn{6}{|l|}{ Closed holes } \\
\hline Mean gain (ETDRS lines) & 1.9 & & 2.1 & & \\
\hline VA achieved (\% patients) & $>20 / 60(54 \%)$ & & $>20 / 40(31 \%)$ & & \\
\hline \multicolumn{6}{|c|}{ Metamorphopsia (no. of amsler squares) } \\
\hline & $62 \pm 65(P=0.008)$ & $29 \pm 63$ & $55 \pm 68(P=0.001)$ & $\begin{array}{l}18 \pm 46 \text { (Wilcoxon } \\
\text { signed ranks test) }\end{array}$ & 0.472 \\
\hline \multicolumn{6}{|l|}{ Contrast sensitivity } \\
\hline (log units) & $1.37 \pm 0.25(P=0.282)$ & $1.28 \pm 0.33$ & $1.39 \pm 0.31(P=0.777)$ & $\begin{array}{l}1.28 \pm 0.33 \text { (Wilcoxon } \\
\text { signed ranks test) }\end{array}$ & 0.525 \\
\hline
\end{tabular}

ETDRS, Early Treatment Diabetic Retinopathy Study; MHS, macular hole surgery; VA, visual acuity.

Table 3 Comparison of mean change in VFQ-25 scores following macular hole surgery with and without prone positioning using Wilcoxon signed ranks test

\begin{tabular}{|c|c|c|c|c|c|}
\hline \multirow[t]{2}{*}{ Questionnaire scale } & \multicolumn{2}{|c|}{ Posture after MH surgery } & \multicolumn{2}{|c|}{ No posture after MH surgery } & \multirow[t]{2}{*}{ P-value } \\
\hline & $\mathrm{N}$ & Mean (SD) & $\mathrm{N}$ & Mean (SD) & \\
\hline \multicolumn{6}{|l|}{ VFQ-25 } \\
\hline General health & 25 & $7.95(23.3)$ & 16 & $6.25(17.6)$ & 0.91 \\
\hline General vision & 25 & 13.6 (15.6) & 16 & 7.50 (17.3) & 0.48 \\
\hline Ocular pain & 25 & $3.4(12.3)$ & 16 & $0.00(9.43)$ & 0.39 \\
\hline Near activities & 25 & $7.95(19.6)$ & 16 & $5.20(19.9)$ & 0.50 \\
\hline Distance activities & 25 & $2.8(18.8)$ & 16 & $2.6(16.5)$ & 0.53 \\
\hline Social functioning & 25 & $4.54(14.7)$ & 16 & $3.11(11.1)$ & 0.68 \\
\hline Mental health & 25 & $11.9(24.3)$ & 16 & $2.84(33.18)$ & 0.32 \\
\hline Role difficulties & 25 & $8.04(19.8)$ & 16 & $9.38(35.8)$ & 0.65 \\
\hline Dependency & 25 & $6.34(18.9)$ & 16 & $4.1(10.2)$ & 0.55 \\
\hline Driving & 13 & $2.78(13.8)$ & 8 & $6.7(62.5)$ & 0.62 \\
\hline Colour vision & 25 & $3.4(15.9)$ & 16 & $-6.25(17.6)$ & 0.25 \\
\hline Peripheral vision & 25 & $-1.13(24.9)$ & 16 & $-8.75(12.1)$ & 0.53 \\
\hline Composite & 25 & $6.23(12.85)$ & 16 & $6.16(16.81)$ & 0.87 \\
\hline
\end{tabular}

MH surgery, macular hole surgery; SD, standard deviation; VFQ-25, 25-Visual Function Questionnaire. 
Table 4 Intra- and postoperative complication in the posture and no posture groups

\begin{tabular}{|c|c|c|c|}
\hline Complication & Postured & Non-postured & P-value \\
\hline \multicolumn{4}{|l|}{ Retinal tears } \\
\hline Intraoperative (treated) & $3 / 25(12 \%)$ & $2 / 16(12.5 \%)$ & \\
\hline Postoperative & $0 / 25$ & $0 / 16$ & \\
\hline High intraocular pressure ${ }^{a}$ & $7 / 25(28 \%)$ & $4 / 16(25 \%)$ & \\
\hline Development of NS & $15 / 23(65 \%)$ & $13 / 16(81 \%)$ & \\
\hline LOCS unit progression & $0.7 \pm 0.6$ & $0.9 \pm 0.8$ & 0.69 \\
\hline Development of PSC & $1 / 23(4 \%)$ & $5 / 16(31 \%)$ & \\
\hline LOCS unit progression & $0.1 \pm 0.6$ & $2.1 \pm 2.0$ & 0.009 \\
\hline
\end{tabular}

a Postoperative intraocular pressure $>30 \mathrm{mmHg}$ requiring antiglaucoma medication for 1 week. LOCS, Lens Opacities Classification; NS, nuclear sclerosis; PSC, posterior subcapsular cataract.

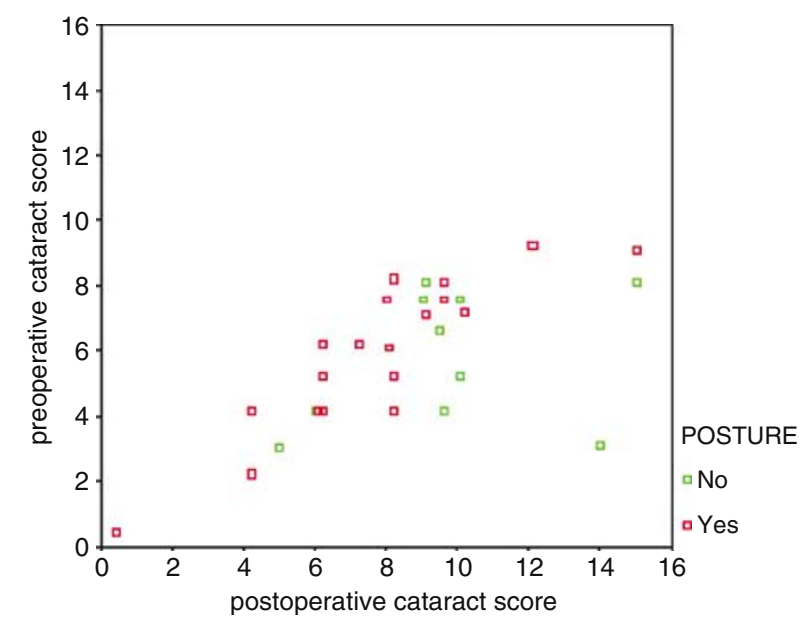

Figure 1 Scatter plot showing the accumulative LOCS score before and following MHS in the posture and non-posture groups.

The progression of cataract following MHS is shown in Figure 1. Patients in group NP developed significantly more severe posterior subcapsular opacities compared with the posturing group $(P=0.009)$. None of the phakic eyes had been noted to have lens opacities before surgery and none had surgery complicated by inadvertent lens touch.

\section{Discussion}

Since the first reported series of FTMH surgery in 1991, ${ }^{11}$ success in terms of anatomical closure has steadily improved, from 58 to $100 \%$ in more recent articles. ${ }^{12,13}$ Recent reports have found short-duration regimens to achieve similar success rates to published studies with longer posturing times. Ellis et $a l^{14}$ showed that 5 days of prone posturing following vitrectomy for FTMH with autologous plate concentrate and C2F6 tamponade afforded success and complication rates comparable to studies with longer posturing times.
It is thought that cortical vitreous peeling during vitrectomy relieves tangential traction on the macula, thus allowing re-approximation of the edges of the hole. $^{15}$

This is further enhanced by gas tamponade. Several mechanisms of action of the gas bubble have been postulated, from exertion of a large floatation force on the macula to preventing exposure of the macular hole to vitreous fluid. ${ }^{4,16,17}$ The former requires strict prone posturing for effect; however, the latter does not.

In an eye with subtotal gas fill, prone posturing prevents the gas bubble from contacting the crystalline lens and isolates the hole from liquid vitreous, allowing a plug or membrane to form. ${ }^{15}$ However, it has been shown that a large long-acting intraocular gas bubble causes the macular hole to be covered by the gas bubble even if the patient is in an upright position. When 16\% C3F8 with initial bubble meniscus height greater than $80 \%$ is used, the meniscus height of the bubble remains greater than $50 \%$, and will cover the macular hole for 1-2 weeks after surgery. ${ }^{4}$

Tornambe $e a^{17}$ first challenged the issue of absolute necessity of prone posturing in MHS. In their study of 33 eyes without posturing, primary and overall closure rates of 79 and $85 \%$, respectively, were achieved using $15 \%$ C3F8 with combined phacovitrectomy and intraocular lens implantation, despite the fact that $21 \%$ of these holes had been present for more than 1 year.

Similarly, Simcock and Scalia, ${ }^{18}$ in their study, reported a $90 \%$ anatomical success rate and a $95 \%$ improvement of at least $0.3 \log$ MAR units for phacovitrectomy surgery without prone posturing for stage 2 and 3 macular holes. This compares favourably with prone postured historical controls.

This is the first controlled study to prospectively assess the role of posturing in vitrectomy for FTMH evaluating systematically the functional, anatomic, subjective, and objective postoperative outcome. We have shown that MHS without prone posturing results in similar closure 
rates to conventional surgery with strict early postoperative posturing. This supports the theory that floatation forces do not play a significant role in hole closure. Our results suggest that the bubble serves to merely isolate the hole from liquid vitreous and thus allow glial proliferation, preretinal membrane growth, and contraction to eventually close the defect.

Our study demonstrates no significant differences in the improvement of objective and subjective measures of visual function between postured and non-postured groups, which is consistent with previous reports. ${ }^{19}$

The most common postoperative complication in our series was development of cataract. The highly significant difference in the progression of posterior subcapsular cataracts between the postured and nonpostured groups (4 and 31\%, respectively) may justify combining phacovitrectomy for all patients who undergo MHS with no posturing.

Advantages of a combined procedure include no further reduction in visual acuity owing to postoperative cataract progression and reduced risk of recurrence of the macular hole following a second procedure. However, it necessitates a longer procedure, and cataract surgery may also be deemed unnecessary if the macular hole remains open. Nevertheless, Tornambe $e t a l^{17}$ found that combined cataract surgery did not adversely affect the retinal procedure or anatomic outcome.

Our findings suggest that macular hole surgery with prone posturing does not provide a functional or anatomic benefit; however, it is associated with slower progression of cataract. Considering that $66 \%$ of patients develop visually significant cataract within 2 years following $\mathrm{MHS}^{20}{ }^{20}$ we suggest that combined phacovitrectomy with no posturing could be the preferred option for all patients undertaking MHS.

Despite the prospective controlled design of our study, we recognise limitations, including the small sample size, the lack of randomisation, and the limited postsurgical follow-up. Nevertheless, our results support those of previous studies challenging the need for posturing. If reproducible in a larger randomised controlled trial, our study suggests that MHS without prone posturing provides comparable anatomic and functional results to conventional MHS with posturing, thus saving patients from the potentially unnessary inconvenience of postoperative prone posturing.

\section{References}

1 Pearce IA, Branley M, Groenewald C, McGalliard J, Wong D. Visual function and patient satisfaction after macular hole surgery. Eye 1998; 12(Part 4): 651-658.
2 Wendel RT, Patel AC, Kelly NE, Salzano TC, Wells JW, Novack GD. Vitreous surgery for macular holes. Ophthalmology 1993; 100: 1671-1676.

3 Thompson JT, Glaser BM, Sjaarda RN, Murphy RP, Hanham A. Effects of intraocular bubble duration in the treatment of macular holes by vitrectomy and transforming growth factor-beta2. Ophthalmology 1994; 101: 1195-1200.

4 Thompson JT, Smiddy WE, Glaser BM, Sjaarda RN, Flynn Jr HW. Intraocular tamponade duration and success of macular hole surgery. Retina 1996; 16(5): 373-382.

5 Johnson RN, Gass JD. Idiopathic macular holes. Observations, stages of formation, and implications for surgical intervention. Ophthalmology 1988; 95(7): 917-924.

6 Gass JDM. Reappraisal of biomicroscopic classification of stages of development of a macular hole. Am J Ophthalmol 1995; 119: 752-759.

7 Folstein MF, Folstein SE, McHugh PR. The Mini-Mental State: a practical method for grating the cognitive state of patients for the clinicians. J Psychiatr Res 1975; 12: 189-198.

8 Klein R, Klein BEK, Moss SE. Visual impairment in diabetes. Ophthalmology 1984; 91: 1-9.

9 Chylack Jr LT, Wolfe JK, Singer DM, Leske MC, Bullimore MA, Bailey IL et al. The lens opacities classification system III. The longitudinal study of cataract study group. Arch Ophthalmol 1993; 111(6): 831-836.

10 Mangione CM, Lee PP, Gutierrez P, Spritzer K, Berry S, Hays RD. Development, reliability, and validity of the 25-item national eye institute visual function questionnaire (VFQ-25). Arch Ophthalmol 2001; 119: 1050-1058.

11 Kelly NE, Wendel RT. Vitreous surgery for idiopathic macular holes. Results of a pilot study. Arch Ophthalmol 1991; 109(5): 654-659.

12 Glaser BM, Michels RG, Kuppermann BD, Sjaarda RN, Pena RA. Transforming growth factor-beta 2 for the treatment of full-thickness macular holes. A prospective randomized study. Ophthalmology 1992; 99(7): 1162-1172; discussion 1173.

13 Liggett PE, Skolik DS, Horio B, Saito Y, Alfaro V, Mieler W. Human autologous serum for the treatment of full-thickness macular holes. A preliminary study. Ophthalmology 1995; 102(7): 1071-1076.

14 Ellis JD, Malik TY, Taubert MA, Barr A, Baines PS. Surgery for full-thickness macular holes with short-duration prone posturing: results of a pilot study. Eye 2000; 14(Part 3A): 307-312.

15 Madreperla SA, Geiger GL, Funata M, de la Cruz Z, Green WR. Clinicopathologic correlation of a macular hole treated by cortical vitreous peeling and gas tamponade. Ophthalmology 1994; 101(4): 682-686.

16 Berger JW, Brucker AJ. The magnitude of the bubble buoyant pressure: implications for macular hole surgery. Retina 1998; 18(1): 84-86; author reply 86-88.

17 Tornambe PE, Poliner LS, Grote K. Macular hole surgery without face-down positioning. A pilot study. Retina 1997; 17(3): 179-185.

18 Simcock PR, Scalia S. Phacovitrectomy without prone posture for full thickness macular holes. $\mathrm{Br}$ J Ophthalmol 2001; 85(11): 1316-1319.

19 Tranos PG, Ghazi-Nouri SM, Rubin GS, Adams ZC, Charteris DG. Visual function and subjective perception of visual ability after macular hole surgery. Am J Ophthalmol 2004; 138(6): 995-1002.

20 Smiddy WE, Feuer W. Incidence of cataract extraction after diabetic vitrectomy. Retina 2004; 24(4): 574-581. 